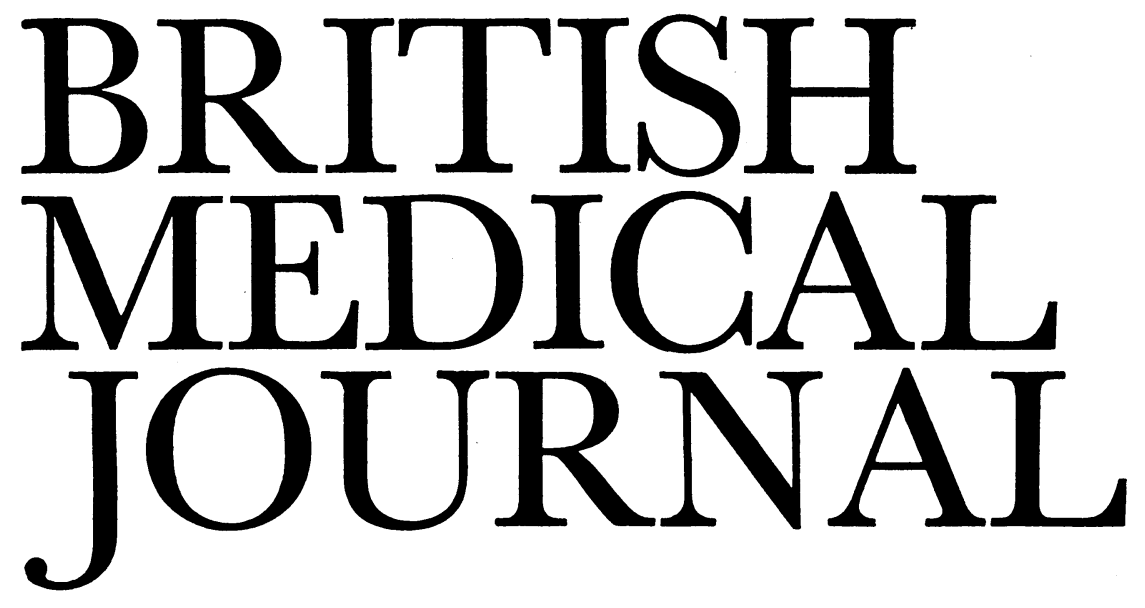

LONDON, SATURDAY 17 APRIL 1982

\title{
Alcoholism: new evidence for a genetic contribution
}

One of the most keenly debated issues in research into alcoholism has been whether genetic factors have an important influence on susceptibility. There is undoubtedly a familial tendency: of nearly 150 studies, all except one have shown higher rates of alcoholism among relatives of alcoholics than in the general population. ${ }^{1}$ Such evidence supported the theory that alcoholism was a distinct disease that could be transmitted from parents to their children. But a familial tendency does not necessarily indicate that a condition is inherited: children learn their parents' attitudes to drinking and may imitate their drinking behaviour. Constraints on excessive drinking are likely to be considerable in some families, non-existent in others.

A considerable reaction was seen against the disease concept of alcoholism in the 1960 s. Surveys had shown that many more people had drinking problems than would be expected from attendance rates for treatment of alcoholism. ${ }^{2}$ Furthermore, problem scores were distributed as a continuum and did not clearly separate "alcoholics" from "normal drinkers." Taken with the epidemiological evidence that the prevalence of alcoholism is related to per caput alcohol consumption, ${ }^{3}$ and hence to the price and availability of alcoholic drinks, genetic factors seemed increasingly unlikely to have an important influence on drinking behaviour and a person's chance of becoming dependent on alcohol. Indeed, $\mathrm{Roe}^{4}$ had found that children who had an alcoholic parent but were adopted soon after birth had very low rates of alcoholism.

The two methods by which a genetic contribution to drinking behaviour may be separated from environmental influences are studies of the drinking habits of adopted children and comparisons of monozygotic (identical) twins with dizygotic (fraternal) twins. In contrast with Roe's experience, Goodwin et $a l^{5}$ found that men having an alcoholic parent but adopted early in life were nearly four times more likely to be alcoholic themselves than the adopted sons of non-alcoholic parents. A similar finding was later reported by $\mathrm{Bohman}^{6}$ in a large-scale adoption study from Sweden. Kaij ${ }^{7}$ reported a higher concordance rate for alcoholism among monozygotic twins (indicating a genetic component). Later studies ${ }^{8-10}$ did not confirm this, however, though the quantity and frequency of alcohol consumption had a substantial heritability. ${ }^{8}$ Using refined techniques of biometric genetics which can take into account the common environment of twins, Clifford and colleagues from the Institute of Psychiatry have shown that the level of alcohol intake is influenced by inherited factors in both sexes and that in men there is a genetic contribution to escape drinking and some alcohol-related problems (C A Clifford, D W Fulker, and R M Murray, "Genetic and environmental influences on drinking patterns in normal twins," presented at the International Conference on Alcoholism and Drug Dependence, Liverpool, 1981).

Two further analyses ${ }^{11} 12$ of the Swedish adoption data have been published recently and provide substantial evidence that alcoholism does, at least in part, have a genetic basis and that there are two distinct patterns of alcohol abuse with different modes of inheritance. The more common type affects both men and women, shows only a moderate degree of transmission from parents to offspring, and is sensitive to environmental factors for its expression; in most cases alcohol abuse is relatively mild. Interestingly, alcoholism is no more prevalent when one of the adoptive parents has a drinking problem. In men the "alcoholic genes" seem to be derived mainly from the father, whereas in women the greater contribution is from the mother. Whether such matrilineal transmission is truly genetic is, of course, questionable since an alcoholic intrauterine environment may affect the developing brain of the fetus and influence sensitivity to alcohol in later life. ${ }^{13}$.

The second type of alcohol abuse is seen only in men, shows a high degree of inheritance, and is usually manifested by more severe alcoholism, often associated with criminal behaviour. The adoptive home seems to have no influence on the genesis of this type of alcoholism, nor have any other environmental factors been implicated. The exact mode of transmission remains to be established; simple Mendelian dominant inheritance seems unlikely since only one in six of the men predisposed to this type of alcohol abuse did have a drink problem by the time they were studied. Others may have become alcoholics subsequently, and other unidentified stresses may determine the expression of this inherited predisposition. One weakness of this work is that the investigators relied largely on official statistics and so could assess only a few environmental stress factors.

A potentially fruitful step would be a search for biological markers of alcoholism in patients with the highly heritable type. If such patients could be identified readily they and members of their family might benefit from selective counselling. Whether a distinction between the two types of alcoholism is useful in practice must await further research, but the evidence 
linking genetic factors with predisposition to alcohol abuse is now very convincing. In Samuel Butler's The Way of All Flesh the hero Ernest Pontifex tries to prevent his children taking up the habits of their alcoholic mother by having them adopted. Current evidence suggests that success was by no means guaranteed.

\section{J B SAUNDERS}

Lecturer,

Liver Unit,

King's College Hospital,

London SE5 9RS

${ }^{1}$ Goodwin DW. Clinical science review. The genetics of alcoholism. Substance and Alcohol Actions/Misuse 1980;1:101-17.

2 Edwards G, Chandler J, Hensman C, Peto J. Drinking in a London suburb. II. Correlates of trouble with drinking among men. Quarterly fournal of Studies on Alcohol 1972 ;suppl 6:94-119.

3 Seeley JR. Death by liver cirrhosis and the price of beverage alcohol. Can Med Assoc f 1960;83:1361-6.

4 Roe A. The adult adjustment of children of alcoholic parents raised in foster-homes. Quarterly Fournal of Studies on Alcohol 1945;5:378-93.

${ }^{5}$ Goodwin DW, Schulsinger F, Hermansen L, Guze SB, Winokur G. Alcohol problems in adoptees raised apart from alcoholic biological parents. Arch Gen Psychiatry 1973;28:238-43.

${ }^{6}$ Bohman M. Some genetic aspects of alcoholism and criminality. A population of adoptees. Arch Gen Psychiatry 1978;35:269-76.

${ }^{7}$ Kaij L. Alcoholism in twins. Stockholm: Almqvist and Wiksells, 1960

${ }^{8}$ Partanen J, Bruun K, Markkanen T. Inheritance of drinking behavior. A study on intelligence, personality, and use of alcohol of adult twins. Helsinki : Finnish Foundation for Alcohol Studies, 1966. (Alcohol Research in the Northern Countries, ser 14.)

9 Jonsson E, Nilsson T. Alkoholkonsumtion hos monozygota och dizygota tvillingpar. Nordisk Hygienisk Tidskrift 1968;49:21-5.

10 Gurling HMD, Clifford CA, Murray RM. Genetic contributions to alcohol dependence and its effect on brain function. In: Gedda L, Parisi P, Nance WA, eds. Twin research. Vol 3. New York: Alan Liss, 1981: 77-87.

11 Cloninger CR, Bohman M, Sigvardsson S. Inheritance of alcohol abuse. Cross-fostering analysis of adopted men. Arch Gen Psychiatry 1981; 38:861-8.

12 Bohman M, Sigvardsson S, Cloninger CR. Maternal inheritance of alcohol abuse. Cross-fostering analysis of adopted women. Arch Gen Psychiatry $1981 ; 38: 965-9$.

${ }^{13}$ Rosett HL. Clinical pharmacology of the fetal alcohol syndrome. In: Majchrowicz E, Noble EP, eds. Biochemistry and pharmacology of ethanol. Vol 2. New York: Plenum Press, 1979:485-509.

\section{Heartburn in pregnancy}

The most frequent form of dyspepsia in pregnancy is heartburn due to reflux into the lower oesophagus, variously estimated to affect $30 \%$ to $70 \%$ of pregnant women. ${ }^{12}$ Heartburn may start in early pregnancy but usually it is a problem of the second and particularly the third trimester. The traditional explanation has been increased intra-abdominal pressure because of the expanding uterus. ${ }^{3}$ Over the past decade, however, this hypothesis has been largely discredited, and the most recent refutation has come from Van Thiel's group in Pittsburgh. ${ }^{4}$ Men with tense ascites were used as a model and measurements obtained of the lower oesophageal sphincter pressure, plasma gastrin concentrations, and basal $\mathrm{pH}$. Before diuresis, when abdominal pressure was increased, the sphincter pressure was also increased. After diuresis, when ascites was no longer a clinical problem, the sphincter pressure was normal. None of the men had heartburn or demonstrable reflux, nor were there any differences in basal fasting concentrations of gastrin or gastric $\mathrm{pH}$ either before or after their diuresis.

Van Thiel et $a l^{4}$ suggest that their findings support the theory that heartburn in pregnancy is due to hormonal factors, and that the progressive rise in concentrations of progesterone or other sex steroids induces a loss of basal oesophageal sphincter pressure allowing acid reflux. There is other more direct evidence for the theory. The same group found no difference in basal gastric $\mathrm{pH}$ or basal and peak acid output at 12,24 , and 36 weeks of pregnancy when compared with postpartum values. In contrast, the lower oesophageal sphincter pressure was reduced at all times in pregnancy, reaching a nadir at 36 weeks. ${ }^{1}$ In an earlier study they found that lower oesophageal sphincter pressure was significantly reduced when women taking sequential oral contraceptives were taking the oestrogen/progestogen moiety. ${ }^{5}$ Other work in early pregnancy showed no difference in lower oesophageal sphincter pressure before and after abortion, but before abortion the responses in sphincter pressure were inhibited by pentagastrin and by a protein meal. ${ }^{6}$ The authors thought that this response was probably mediated by the raised serum concentrations of oestrogens and progesterone.

If hormonal factors cause heartburn in pregnancy the effect may not be solely on the lower oesophageal sphincter. Atlay confirmed relaxation of this sphincter in pregnancy but also found radiographic evidence of incompetence of the pyloric sphincter and concluded that reflux of bile might be an important cause of heartburn. ${ }^{2}$ This suggested that the condition could be treated with dilute hydrochloric acid ${ }^{7}$ and if a patient did not respond to this after seven days then an alkali mixture was prescribed. He claimed a $98 \%$ chance that one of the treatments would relieve the symptoms. This was taken as further evidence that pyloric incompetence and lower oesophageal sphincter incompetence were both implicated in pregnancy heartburn.

Not all authorities accept, however, that hormonal factors are responsible for the heartburn. Hey et $a l^{8}$ point out that serum progesterone concentrations are similar in patients both with and without heartburn and suggest that pregnant women with heartburn have an intrinsically weaker lower oesophageal sphincter than those without. There is also some evidence that heartburn in pregnancy is less common in Nigerians than Caucasians because they are less likely to have displacement of the lower oesophagus into the negative pressure environment of the thorax, ${ }^{9}$ though others dispute this. ${ }^{2}$

Nevertheless, the consensus view is that in pregnancy an altered hormone pattern compromises lower oesophageal sphincter function, allowing reflux with consequent heartburn. There may be an accompanying incompetence of the pyloric sphincter with a reflux of both acid and bile into the oesophagus. The hormonal basis for the syndrome is still a theory and is not proved. Progesterone is clearly the likely culprit, but it remains to be shown whether or not oestrogen priming is needed for any possible effect on the muscle of the lower oesophageal sphincter. ${ }^{10}$

Irrespective of the pathophysiology the clinician's prime interest is treatment. Fortunately in most patients symptoms tend to be mild and can be relieved by a regimen of frequent small meals and avoiding bending or lying down flat. If these measures are ineffective simple antacid preparations such as magnesium trisilicate or aluminium hydroxide gel may be prescribed. Fortunately most cases arise during the second and third trimester, and patients can be reassured that there is no evidence of antacids causing teratogenicity though Martindale ${ }^{11}$ advises against them during any time of pregnancy. This advice is based on the work of Nelson and Forfar, ${ }^{12}$ who found that $6.1 \%$ of mothers who had babies with congenital defects had taken antacids in the first trimester compared with $2.6 \%$ of controls. Nevertheless, looking at the whole of 